\title{
RELACIÓN ENTRE SALARIOS REALES Y PRODUCTIVIDAD REAL EN LA INDUSTRIA MANUFACTURERA COLOMBIANA: \\ ANÁLISIS DE DATOS PANEL 1970-1989 Y 1990-2012
}

ALBERTO SAMPER CRUZ

Universidad Santo Tomás

Maestría en Ciencias Económicas

Bogotá DC

2016 


\title{
RELACIÓN ENTRE SALARIOS REALES Y PRODUCTIVIDAD REAL EN LA INDUSTRIA MANUFACTURERA COLOMBIANA: \\ ANÁLISIS DE DATOS PANEL 1970-1989 Y 1990-2012
}

\section{ALBERTO SAMPER CRUZ}

Trabajo de investigación presentado a:

\author{
Dr. ÁLVARO ANDRÉS VERNAZZA PÁEZ \\ Director, Maestría en Ciencias Económicas
}

Requisito para optar al Título de Magíster en Ciencias Económicas

\author{
Asesor \\ Dr. HENRY LAVERDE RODAS \\ Universidad Santo Tomás \\ Maestría en Ciencias Económicas \\ Bogotá DC
}

2016 


\section{CONTENIDO}

Página

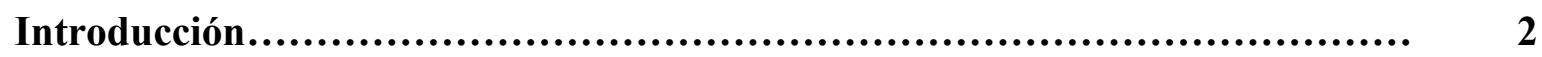

1. El problema y sus contextos.............................................. 4

2. Evolución del sector industrial: 1970-1989. Importancia en la economía colombiana..................................................................... ${ }^{7}$

3. Comportamiento industrial: 1990-2012. Apertura y política neoliberal................ 11

4. Marco metodológico y modelo econométrico.................................. 17

5. Resultados del trabajo empírico. Análisis econométrico...................... 19

Conclusiones..................................................................... 30

Referencias..................................................................... 32

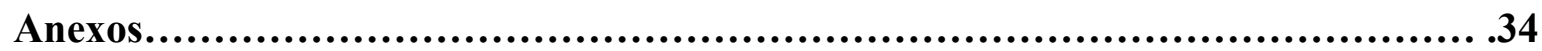




\section{Relación entre salarios reales y productividad real en la industria manufacturera colombiana: \\ Análisis de datos panel 1970-1989 y 1990-2012}

Los trabajadores gastan todo lo que ganan y los capitalistas ganan todo lo que gastan.

Kalecky (1956)

\section{Resumen}

El objetivo de este estudio es investigar la relación de largo plazo entre los salarios reales y la productividad real del factor trabajo en el sector industrial colombiano. Se trata de comprobar que, a partir de 1990, los cambios estructurales de la economía colombiana, específicamente con las reformas laborales para lograr una flexibilización del mercado del trabajo, han repercutido desfavorablemente en los salarios reales, según el comportamiento de la productividad laboral en dicho sector. En tal sentido, se analizan datos de panel para los periodos 1970 - 1989 y 1990 - 2012, a nivel de las 28 agrupaciones industriales según los tres dígitos de la CIIU. Se encontró que las series de salarios y productividad presentan cointegración en los dos periodos analizados. Se evidenció, además, que durante el primer periodo existe un efecto de causalidad positiva de la productividad sobre los salarios, en tanto que en el otro, la relación de causalidad se presenta con un efecto negativo.

\section{Palabras clave}

Industria manufacturera, panel de pruebas de cointegración, panel de pruebas de raíz unitaria, productividad laboral, salario real. 


\section{Introducción}

Uno de los criterios para la distribución equitativa del ingreso tiene que ver con la productividad generada por el factor trabajo, ya que esta debe conducir a la satisfacción de las necesidades básicas, a una mejora continua de la calidad de vida y a condiciones de equidad social.

No obstante tal premisa, una serie de reformas en la economía colombiana, realizadas entre 1990 y 2012, no han permitido cumplir con el principio del reparto equitativo de la riqueza. La liberación e implementación de las políticas neoliberales a partir de ese primer año, conllevaron a la flexibilización laboral con el fin de facilitar la competencia en un mercado globalizado. Sus efectos fueron regresivos y nefastos, especialmente en el sector industrial. En efecto, las leyes 50 de 1990 y 789 de 2002 condujeron a la reducción de costos salariales y aumentos de la productividad laboral. Esto significó precarización de las condiciones laborales de los trabajadores al tiempo que se incrementaba la tasa de ganancia para las empresas, pues la participación de los salarios reales en el valor agregado real total de la industria cayó del $25 \%$ en el año 90 del siglo pasado al 12\% en el año 12 de la actual centuria.

Adicional a los resultados enunciados, las medidas de flexibilización han aumentado la informalidad en la industria, como producto del despido de gran cantidad de la fuerza de trabajo. Esto llevó a que una parte de desempleados se viera obligada a trabajar en forma independiente o temporal; en algunas ocasiones, para las mismas empresas, a manera de tercerización. Tal situación explica la creación de numerosas firmas satélites o maquilas cuyo trabajo es realizado en condiciones de subsistencia, sin seguridad social y donde la remuneración a los trabajadores depende solo del volumen de producción por periodo de tiempo, lo que repercute en una reducción substancial del salario real.

Dado que el objetivo del presente trabajo es analizar la evolución del salario en la industria manufacturera ante las reformas laborales que pretendían crear nuevos puestos de trabajo, y cuantificar el efecto de la productividad laboral sobre la variable objetivo, aquí se especifica, estima y verifica un modelo econométrico que relaciona el salario real en función de la productividad real. El estudio se llevó a cabo a nivel de las 28 agrupaciones industriales seleccionadas según la Clasificación Industrial Internacional Uniforme (CIIU) de tres dígitos. En consecuencia, se compara en forma dinámica dicho comportamiento durante el lapso de 1990 a 2012, en comparación con lo experimentado entre 1970 y 1989 , cuando el modelo económico se sustentó en el mercado interno y en la sustitución de 
importaciones. Por la naturaleza del modelo que estudia variables de corte transversal y de series del tiempo, el análisis requiere la implementación de una técnica econométrica de datos de panel y las diferentes pruebas requeridas para series económicas en las dimensiones referidas, tales como pruebas de raíz unitaria y cointegración. Así, se puede aplicar, finalmente, el modelo completamente ampliado de mínimos cuadrados ordinarios (FMOLS) que cuantifica y valida la relación funcional salarios- productividad.

El documento contiene cinco capítulos organizados de la siguiente manera: el primero presenta el problema y sus contextos; el segundo, la evolución del sector manufacturero en el lapso 1970 - 1989; en el tercero se analiza el comportamiento del sector industrial durante el periodo 1990 - 2012. Por su parte, bajo el título 4 se exponen el marco metodológico y el estudio econométrico para, en el apartado 5 dar a conocer los resultados de los modelos y del trabajo empírico. Al final se formulan las principales conclusiones del caso. 


\section{El problema y sus contextos}

Entre las reformas de la economía que se impulsaron en Colombia a partir de 1990, con el fin de consolidar su apertura y liberación, se encuentra la referente al tema laboral. Esta trajo consigo serias dificultades en cuanto a la generación de empleo formal y el deterioro de la remuneración salarial en el sector industrial. Según Tejedor (2013), la flexibilización laboral, cuyo antecedente principal fue la Ley 50 de 1990, ha incrementado el número de trabajadores independientes y temporales, los cuales han visto disminuido su salario al tener que asumir personalmente el pago de la seguridad social. Por su parte, con la aplicación de la Ley 789 de 2002, los obreros comprimieron sus ingresos debido a la disminución en el pago de las horas extras, festivos, dominicales y el recorte de la jornada nocturna. Con la Ley 797 de 2003 se aumentaron las semanas de cotización al sistema de pensiones, hecho que prorrogó la jubilación de muchos asalariados.

Los temas de debate de la política salarial en el país tienen que ver con la legislación laboral y el efecto de la productividad sobre los salarios, en particular desde la liberación económica. Máxime cuando se trata de discutir, mediante concertación entre gobierno, empresa y trabajadores, el reajuste del salario mínimo. En el presente estudio, interesa, por tanto, estimar y verificar el efecto de la productividad laboral sobre la evolución de los salarios reales, cuestión que se lleva a cabo mediante el análisis comparativo del antes y después del cambio de modelo de la economía colombiana, cuando se pasó a los programas aperturistas y la política neoliberal que, como se anotó, operan desde 1990.

El largo periodo examinado, después de las reformas de 1990, durante el cual se expuso al sector industrial colombiano a la competencia externa, permite evaluar la efectividad de las medidas relacionadas con el comercio internacional, así como con el orden interno, en cuanto a la flexibilización del mercado laboral y la relación dinámica causal entre salarios y productividad. Una aproximación a los resultados se refleja en un análisis de Eduardo Sarmiento Palacio $(2014,13)$ cuando plantea que

Las políticas de comercio internacional colocan los salarios por debajo de la productividad para poder competir con el resto del mundo; también, toda clase de políticas que atentan contra el salario, por ejemplo, el ajuste del salario mínimo siempre se hace por debajo del aumento de la productividad del trabajo, lo cual les significa mayores ganancias a los empresarios.

En ese sentido, bajo la especificación del modelo salario-productividad, se explican el concepto de la eficiencia y los fenómenos económicos que se derivan de este enfoque. El incremento en la productividad debe significar mejores niveles salariales, constituyendo así 
la clave del crecimiento económico y un indicador de los niveles de vida, dado que se mide en términos reales. Los salarios, en tanto factor dinamizador de la demanda efectiva, contribuyen a la generación del valor agregado, importante indicador de los ingresos de un sector o un país. Por consiguiente, del nivel de salarios y su poder adquisitivo depende la satisfacción de las necesidades de la población y su oferta competitiva en un mercado globalizado. Al respecto, Méndez $(1997,171)$ afirma:

A medida que la productividad se incrementa por la mecanización, automatización y cambios en los métodos de trabajo, también el salario se va modificando en cuanto a su forma (diferentes tipos de salarios) y en cuanto a su monto (los trabajadores más productivos generalmente reciben mayores salarios).

Ahora bien, en Colombia existen pocos estudios de investigación empírica sobre la relación de largo plazo entre salarios y productividad del trabajo en la industria manufacturera. Entre los publicados se halla la investigación desarrollada por Méndez y Hernández (2014), quienes analizaron este tipo de relación en 24 departamentos, durante los años 1992 a 2010. Los autores realizaron pruebas de raíz unitaria y cointegración para determinar si las series comparten tendencias estocásticas comunes. Ellos estimaron también un modelo de vectores autorregresivos (VAR), que les permitió hacer un análisis de causalidad y sensibilidad, y así determinar cuál es el efecto futuro de los choques en cualquier variable del modelo. Los hallazgos empíricos de dicho estudio llevan a concluir que en Colombia existe un conflicto en la distribución de la riqueza porque los cambios en la productividad no se reflejan en incrementos de los salarios de los trabajadores.

A nivel internacional afloran otros resultados. Por ejemplo, los estudios de Zhang y Smith (2012) resaltan las empresas canadienses de mayor productividad en lo transcurrido de la globalización: son las exportadoras y las que invierten en el extranjero, las cuales, a la par, presentan alta correlación entre la productividad laboral y los salarios. Con dichos análisis constataron que el proceso de liberación y apertura ha conducido, por la vía de mayor competitividad y reducción de costos en un mercado globalizado, a una dualidad de sectores; vale decir, los que lograron tecnificación y los rezagados en productividad.

A su vez, Zhanga y Liua (2013) realizaron una investigación sobre la evolución de los salarios en relación con la productividad laboral y otras variables en la industria manufacturera china, durante el periodo 1998 - 2007 y distinguieron entre las empresas de propiedad estatal y las privadas. Los autores comprobaron que existe una correlación positiva y significativa entre los salarios y la productividad del trabajo en los primeros años, pero esta se torna débil y poco significativa hacia el final del periodo examinado, cuando las tasas de crecimiento de la productividad laboral son mayores que las tasas de crecimiento de los salarios, diferencial que se ha ampliado con el tiempo. 
De igual manera, el trabajo de Bhattacharya et ál. (2010) tiene que ver con la correspondencia de largo plazo entre la productividad laboral y el empleo, y entre la productividad laboral y los salarios reales en el sector manufacturero de la India. Ellos utilizan datos de panel para 17 agrupaciones industriales de dos dígitos en la CIIU, durante el periodo 1973 - 1974 a 1999 - 2000. Encontraron que las duplas productividad-salarios y productividad-empleo en el panel están cointegradas para todas las agrupaciones industriales, y en el largo plazo existe evidencia clara de que el aumento de los salarios reales y el empleo incrementan la productividad laboral en el sector manufacturero de la India. Después de la liberación, la competencia de otros países asiáticos ha incrementado tanto las oportunidades de empleo como los salarios reales en el sector. Esto es cierto, tanto para las industrias productoras para el mercado interno como las orientadas a la exportación.

Los planteamientos de este último trabajo constituyen la base del estudio propuesto para la presente investigación con algunas modificaciones. Aquí se asigna la variable dependiente en el modelo de regresión a los salarios reales y como independiente la productividad laboral a nivel de los subsectores o agrupaciones industriales. Así mismo, no solo se analiza el periodo posterior a la apertura y liberalización de la economía, también se contrasta con los veinte años anteriores caracterizados por la influencia de un modelo proteccionista y de gran participación en el mercado interno.

Los modelos y metodología econométrica implementados para cuantificar la relación propuesta en los dos periodos de referencia corresponden a los de regresión simple, para medir la causalidad de la productividad real del factor trabajo sobre los salarios reales a través de un panel de datos. Para esto, se tomaron las cifras a nivel de los 28 subsectores o agrupaciones industriales de la CIIU versión 2 y 3 adaptada para Colombia. Los dos lapsos de estudio, considerados de largo plazo, transcurren, el primero durante veinte años, de 1970 a 1989, y el segundo, durante veintitrés años, de 1990 a 2012. Esto posibilita tener una idea clara del efecto del cambio de modelo económico en un sector específico y de gran importancia en el desarrollo económico de un país, como es la industria manufacturera. Según García $(2002,119)$ :

No existe ningún antecedente en el mundo, donde el desarrollo haya sido consolidado con base en un sector productivo diferente al industrial. Las experiencias más recientes, en el sudeste asiático y en China, confirman el papel estratégico del sector industrial en el crecimiento y en la transformación productiva con mejoramiento de los niveles de bienestar social. 


\section{Evolución del sector industrial: 1970 - 1989. Importancia en la economía colombiana}

Con base en los planteamientos expuestos, a continuación se examina de manera descriptiva el comportamiento y evolución de las principales variables de la industria manufacturera entre los años 1970 y 1989, lapso durante el cual la producción se dedicó a abastecer el mercado interno. Su actividad se sustentó en la sustitución de importaciones, con miras a lograr un desarrollo integral del país. Tal política se cimentó en el crecimiento industrial, al considerar este sector como el líder en la generación de empleo así como en la diversificación de la producción con miras a generar excedentes exportables y jalonar el crecimiento de los demás sectores de la economía.

Como puede observarse en la tabla 1, las tasas de crecimiento de la industria manufacturera superaron permanentemente, durante el periodo referido, el crecimiento del PIB total a precios constantes de 1975. En efecto, tomando el crecimiento promedio anual de estas variaciones porcentuales, la industria lo hizo a una tasa del 5,02 \%, en tanto que el PIB total solo alcanzó el 4,57\%. Por su parte, el sector agropecuario creció a un ritmo anual del 3,58 \% mientras el financiero lo hizo al 3,16 \%. Esta evolución de la industria indica su creciente importancia en la economía en general, pues su alta participación dentro del PIB se elevó al 20\% en los primeros años de la década del 70, subió al $23 \%$ entre 1972 y 1979, para, finalmente, estabilizarse en el $21 \%$ al final de la década del 80.

Este comportamiento de contribución del sector industrial a la economía contrasta con el registrado por el sector agropecuario. Este último participó con el $25 \%$ al inicio de los años 70 , se redujo al $23 \%$ durante parte de los 80 y finalmente se ubicó en $21 \%$ hacia 1989. Tal desempeño de los dos sectores de mayor contribución al PIB concuerda con las teorías del desarrollo para los países emergentes, en el sentido de experimentar una reducción paulatina de la contribución del sector agropecuario y un crecimiento simultáneo de la participación del sector industrial. El tercer sector en importancia corresponde al financiero, cuyo promedio se estabilizó en el $12 \%$. 
Tabla 1. PIB según sectores a precios constantes de 1975 (Millones de \$)

\begin{tabular}{|l|c|c|r|r|r|r|r|r|r|r|c|}
\hline Años & $\begin{array}{c}\text { PIB } \\
\text { Total }\end{array}$ & $\begin{array}{c}\text { Var } \\
\text { \% }\end{array}$ & Agropecuario & $\begin{array}{c}\text { Var } \\
\text { \% }\end{array}$ & $\begin{array}{c}\text { Part. } \\
\text { \% }\end{array}$ & Industria & $\begin{array}{c}\text { Var } \\
\boldsymbol{\%}\end{array}$ & $\begin{array}{c}\text { Part. } \\
\boldsymbol{\%}\end{array}$ & Financiero & $\begin{array}{c}\text { Var } \\
\text { \% }\end{array}$ & $\begin{array}{c}\text { Part. } \\
\%\end{array}$ \\
\hline 1970 & 307.496 & 6,21 & 77.893 & 3,43 & 0,25 & 61.866 & 6,97 & 0,20 & 41.612 & 3,79 & 0,14 \\
\hline 1971 & 325.825 & 5,96 & 78.529 & 0,82 & 0,24 & 65.783 & 6,33 & 0,20 & 43.350 & 4,18 & 0,13 \\
\hline 1972 & 350.813 & 7,67 & 84.667 & 7,82 & 0,24 & 79.046 & 20,16 & 0,23 & 45.089 & 4,01 & 0,13 \\
\hline 1973 & 374.398 & 6,72 & 86.669 & 2,36 & 0,23 & 85.789 & 8,53 & 0,23 & 46.827 & 3,85 & 0,13 \\
\hline 1974 & 395.910 & 5,75 & 91.477 & 5,55 & 0,23 & 92.936 & 8,33 & 0,23 & 48.565 & 3,71 & 0,12 \\
\hline 1975 & 405.108 & 2,32 & 96.766 & 5,78 & 0,24 & 94.086 & 1,24 & 0,23 & 50.304 & 3,58 & 0,12 \\
\hline 1976 & 424.263 & 4,73 & 99.720 & 3,05 & 0,24 & 98.210 & 4,38 & 0,23 & 52.042 & 3,45 & 0,12 \\
\hline 1977 & 441.906 & 4,16 & 102.979 & 3,27 & 0,23 & 99.625 & 1,44 & 0,23 & 53.780 & 3,34 & 0,12 \\
\hline 1978 & 479.335 & 8,47 & 111.336 & 8,12 & 0,23 & 109.559 & 9,97 & 0,23 & 55.518 & 3,23 & 0,12 \\
\hline 1979 & 505.119 & 5,38 & 116.730 & 4,84 & 0,23 & 116.264 & 6,12 & 0,23 & 57.257 & 3,13 & 0,11 \\
\hline 1980 & 525.765 & 4,09 & 119.314 & 2,21 & 0,23 & 117.672 & 1,21 & 0,22 & 58.995 & 3,04 & 0,11 \\
\hline 1981 & 537.736 & 2,28 & 123.135 & 3,20 & 0,23 & 114.556 & $-2,65$ & 0,21 & 60.733 & 2,95 & 0,11 \\
\hline 1982 & 542.836 & 0,95 & 120.803 & $-1,89$ & 0,22 & 112.906 & $-1,44$ & 0,21 & 62.472 & 2,86 & 0,12 \\
\hline 1983 & 551.380 & 1,57 & 124.196 & 2,81 & 0,23 & 114.197 & 1,14 & 0,21 & 64.210 & 2,78 & 0,12 \\
\hline 1984 & 569.855 & 3,35 & 126.375 & 1,75 & 0,22 & 121.035 & 5,99 & 0,21 & 65.948 & 2,71 & 0,12 \\
\hline 1985 & 587.561 & 3,11 & 128.456 & 1,65 & 0,22 & 124.610 & 2,95 & 0,21 & 67.687 & 2,64 & 0,12 \\
\hline 1986 & 621.781 & 5,82 & 132.792 & 3,38 & 0,21 & 132.021 & 5,95 & 0,21 & 69.425 & 2,57 & 0,11 \\
\hline 1987 & 655.164 & 5,37 & 141.270 & 6,38 & 0,22 & 140.229 & 6,22 & 0,21 & 71.163 & 2,50 & 0,11 \\
\hline 1988 & 681.791 & 4,06 & 145.182 & 2,77 & 0,21 & 142.887 & 1,90 & 0,21 & 72.901 & 2,44 & 0,11 \\
\hline 1989 & 705.068 & 3,41 & 151.423 & 4,30 & 0,21 & 150.913 & 5,62 & 0,21 & 74.640 & 2,39 & 0,11 \\
\hline
\end{tabular}

Fuente: Elaboración propia con base en Cuentas Nacionales DANE

Con la investigación se evidenció el papel que cumplió la industria manufacturera en el crecimiento y desarrollo del país durante las dos décadas estudiadas. Sin duda, fue el sector de mayor generación de empleo formal, según las condiciones de la legislación laboral que prevalecieron hasta el final de los ochenta. Esta favorecía al trabajador, entre otros aspectos, con el derecho a la huelga y la conformación de los sindicatos, a contratos de trabajo, auxilios de enfermedad, cesantía y vacaciones remuneradas. Dicho sector también se destacó por ser el de mayor incidencia en la diversificación de las exportaciones, pues transformó progresivamente la fase de producción de bienes de consumo final por la de intermedios y, en su mayor desarrollo, por la de bienes de capital. De este modo, logró competir en un entorno globalizado y jalonar simultáneamente a los demás sectores como el agropecuario y de servicios.

\subsection{El empleo}

El empleo generado por la industria manufacturera durante los años de estudio creció a un ritmo anual del 2,14 \%, al pasar de 347.251 personas en 1970 a 492.672 en 1989. Los años de mayor demanda de empleo fueron los siguientes: 1978, con 500.605; 1979, con $516.674 ; 1980$, con 516.269, y 1981, con 501.035. 
En el gráfico 1 se aprecia la evolución del empleo en la industria manufacturera total, cuyo comportamiento coincide con la fase del ciclo del PIB. En efecto, las mayores tasas de crecimiento del empleo de los años 78, 79 y 80 concuerdan con las más altas variaciones del PIB del 8,47 \%, 5,38\% y 4,09\% respectivamente.

Gráfico 1. Personal ocupado en la industria colombiana entre 1970 y 1989

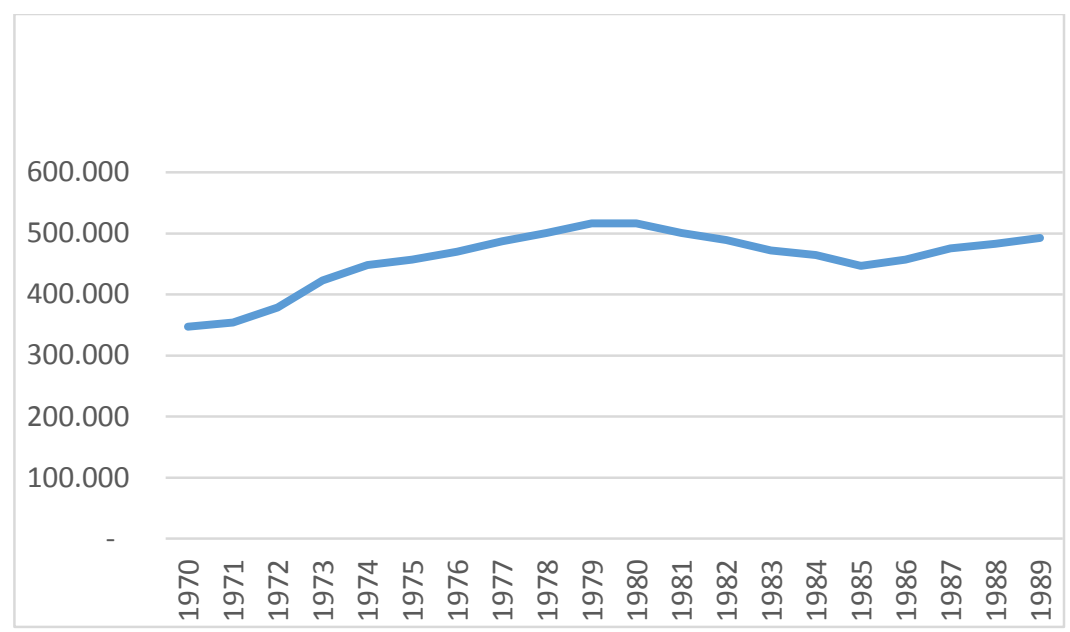

Fuente: DANE. Encuesta Anual Manufacturera

\subsection{Salarios y productividad}

En cuanto a la productividad real laboral (precios constantes de 1990), al tomar el promedio de la variación anual durante los veinte años, se registra una tasa de crecimiento del $3 \%$. Dicha evolución contrasta con la variación del salario real en igual periodo al crecer a una cifra superior $(3,58 \%)$. Tal situación se puede explicar por la consolidación de un mercado interno, en tanto se reactivó la demanda efectiva, precisamente por las condiciones favorables relacionadas con los salarios y las prestaciones sociales, factores que repercutieron en una mejor capacidad adquisitiva y en un mayor consumo final por parte de las familias. Al cuantificar dicha relación para los veinte años en cuestión, en el total de la industria, se destaca la alta correlación de 0,94. Además, se registró un 0,88 como coeficiente de determinación de los salarios en función de la productividad, lo cual indica una alta dependencia de los salarios con respecto a la otra variable. 
En el gráfico 2 se pueden observar las mayores tasas de crecimiento de los salarios frente a la productividad, con excepción de los años 85 y 86 del siglo pasado, cuando las altas tasas de inflación, de alrededor del $25 \%$, afectaron los salarios reales. El crecimiento más importante de los salarios durante el periodo examinado se indica en el año 1978, cuando ocurre a una tasa del 17,42 \%, en tanto que la productividad solo creció en 3,09\%, en razón a las altas tasas de empleo de dichos años, tal como se mencionó anteriormente.

Gráfico 2. Variación porcentual de los salarios y la productividad en la industria: 1970-1989

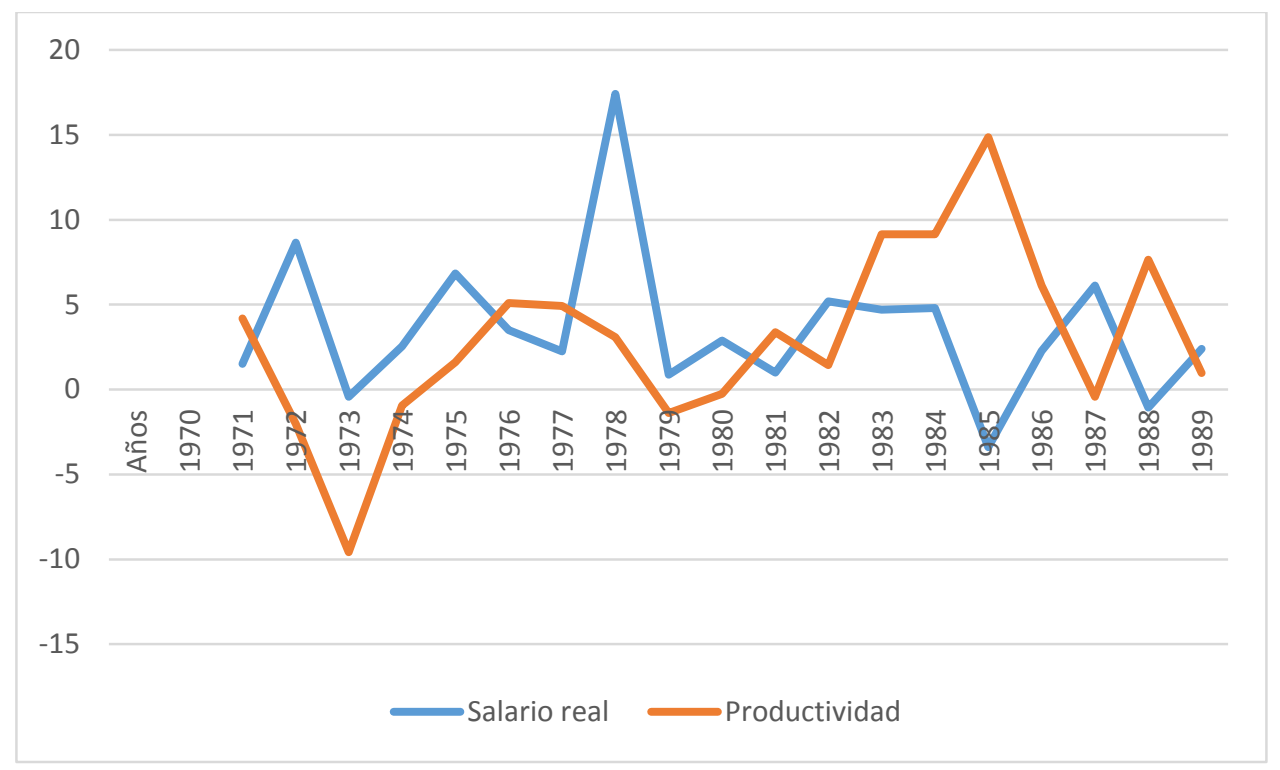

Fuente: Elaboración propia.

El importante repunte del poder adquisitivo de los salarios reales en 1978 obedeció a la respuesta del gobierno del presidente Alfonso López a una de las mayores protestas sindicales de la historia colombiana, como fue el paro cívico nacional de 1977.

\subsection{La Producción bruta}

En cuanto a la producción bruta del sector industrial, que incluye el consumo intermedio y el valor agregado, se advierte una tasa significativa de crecimiento promedio anual del $4,84 \%$, ligeramente superior a la registrada por el PIB total $(4,57 \%)$. El componente consumo intermedio presenta mayor dinámica al crecer a un ritmo del 5,16\%, mientras el valor agregado lo hace a un 4,44\%. Durante los veinte años de estudio, la participación del consumo intermedio en la producción total se mantuvo alrededor del $60 \%$, en tanto que al valor agregado le corresponde el $40 \%$. Este porcentaje de participación del consumo intermedio pertenece básicamente a bienes intermedios de origen nacional, dado que el modelo estuvo sustentado en la sustitución de importaciones. 


\section{Comportamiento industrial: 1990-2012. Apertura y política neoliberal}

A continuación se establecerá una visión descriptiva del comportamiento industrial entre los años 1990 - 2012. El objetivo es comparar los dos periodos caracterizados por modelos completamente disímiles. Se trata de evaluar las variables macroeconómicas y, específicamente, el comportamiento de la industria, las principales transformaciones de este sector y sus repercusiones sobre la economía en general.

A partir de 1990, la economía colombiana entró a operar en un escenario de internacionalización, producto de la globalización. Esto implicó una serie de reformas que recomendaban la liberación de las economías para lograr mayor productividad y tecnificación, como medio para competir en los mercados internacionales y alcanzar así mayores tasas de crecimiento del aparato productivo.

La concepción de renovación y revaluación de las instituciones vigentes en las economías en vías de desarrollo surgió a partir de la política neoliberal, cuya idea fundamental es reducir al mínimo la intervención del Estado, propendiendo por una mayor libertad y un campo de acción más amplio; en otras palabras, retomar las ideas de la escuela liberal o inglesa propuesta por Adam Smith, donde las leyes del mercado se rigen por el libre juego de la oferta y la demanda.

Según Sierra (2001, 286):

La teoría neoliberal defiende la internacionalización de la economía mediante el mecanismo libre de la oferta y la demanda, la libertad de mercados, la propiedad privada y supone que todo intervencionismo de estado se limita a una simple medida que por ningún motivo estorbe a la libre empresa.

El gran reto para los países que asumieron tales cambios estructurales era lograr su efectividad, a partir de valorar su situación en materia económica, social y política, en comparación con la existente en los países desarrollados, en tanto que desde allí se logró imponer dichos postulados, ratificados luego en Colombia por la Constitución nacional de 1991.

A nivel macroeconómico, entre 1990 y 2012, la situación con respecto a las cifras del comportamiento de la economía colombiana y, particularmente de sus sectores más importantes en contribución al crecimiento del PIB, es preocupante por su pérdida de dinamismo. Las tasas de variación anual fueron menores a las registradas en los veinte años anteriores. En efecto, tal como se aprecia en la tabla 2, el PIB total, a precios constantes de 
1994, creció a un ritmo anual del 3,54 \%, cuando entre 1970 y 1989 ocurrió a una tasa del 4,57 \%. Esta disminución del crecimiento promedio se debió en gran parte a la caída durante 1999 del 4,29\%. Sin embargo, a partir del segundo año del presente siglo, se inició una etapa de recuperación, cuya dinámica alcanzó las tasas más altas de la década en 2006 con $6,70 \%$ y en 2007 con el 6,90\%. El sector agropecuario, por su parte, solo creció al $1,01 \%$ en promedio anual, en contraste con el 3,58 \% en el lapso precedente. La industria redujo, igualmente, su crecimiento promedio anual al 1,02 \%, mucho menor al PIB total, cuando antes fue del 5,02\%; el sector financiero registró un promedio anual del $1,05 \%$ frente al $3,16 \%$.

Tabla 2. PIB según sectores, a precios constantes de 1994 (en miles de millones de \$)

\begin{tabular}{|r|r|r|r|r|r|r|r|r|r|r|r|}
\hline Años & $\begin{array}{c}\text { PIB } \\
\text { Total }\end{array}$ & $\begin{array}{c}\text { Var } \\
\text { \% }\end{array}$ & Agropecuario & $\begin{array}{c}\text { Var } \\
\text { \% }\end{array}$ & Part.\% & Industria & $\begin{array}{c}\text { Var } \\
\text { \% }\end{array}$ & Part. \% & Financiero & $\begin{array}{c}\text { Var } \\
\text { \% }\end{array}$ & Part.\% \\
\hline 1990 & 56.873 & & 9.167 & & 0,16 & 10.262 & & 0,18 & 2.440 & & 0,04 \\
\hline 1991 & 58.223 & 2,37 & 9.424 & 1,03 & 0,16 & 10.286 & 1,00 & 0,18 & 2.693 & 1,10 & 0,05 \\
\hline 1992 & 60.758 & 4,35 & 9.603 & 1,02 & 0,16 & 10.072 & 0,98 & 0,17 & 2.777 & 1,03 & 0,05 \\
\hline 1993 & 64.226 & 5,71 & 9.767 & 1,02 & 0,15 & 9.946 & 0,99 & 0,15 & 3.105 & 1,12 & 0,05 \\
\hline 1994 & 67.532 & 5,15 & 10.015 & 1,03 & 0,15 & 10.127 & 1,02 & 0,15 & 3.633 & 1,17 & 0,05 \\
\hline 1995 & 71.046 & 5,20 & 10.390 & 1,04 & 0,15 & 10.726 & 1,06 & 0,15 & 4.303 & 1,18 & 0,06 \\
\hline 1996 & 72.506 & 2,06 & 10.261 & 0,99 & 0,14 & 10.528 & 0,98 & 0,15 & 4.880 & 1,13 & 0,07 \\
\hline 1997 & 74.994 & 3,43 & 10.328 & 1,01 & 0,14 & 10.572 & 1,00 & 0,14 & 5.079 & 1,04 & 0,07 \\
\hline 1998 & 75.421 & 0,57 & 10.332 & 1,00 & 0,14 & 10.541 & 1,00 & 0,14 & 4.791 & 0,94 & 0,06 \\
\hline 1999 & 72.250 & $-4,20$ & 10.327 & 1,00 & 0,14 & 9.659 & 0,92 & 0,13 & 4.057 & 0,85 & 0,06 \\
\hline 2000 & 74.364 & 2,93 & 10.725 & 1,04 & 0,14 & 10.784 & 1,12 & 0,15 & 3.755 & 0,93 & 0,05 \\
\hline 2001 & 75.458 & 1,47 & 10.685 & 1,00 & 0,14 & 10.947 & 1,02 & 0,15 & 3.834 & 1,02 & 0,05 \\
\hline 2002 & 76.917 & 1,93 & 10.698 & 1,00 & 0,14 & 11.237 & 1,03 & 0,15 & 3.942 & 1,03 & 0,05 \\
\hline 2003 & 79.884 & 3,86 & 10.991 & 1,03 & 0,14 & 11.750 & 1,05 & 0,15 & 4.348 & 1,10 & 0,05 \\
\hline 2004 & 83.772 & 4,87 & 11.211 & 1,02 & 0,13 & 12.623 & 1,07 & 0,15 & 4.725 & 1,09 & 0,06 \\
\hline 2005 & 87.727 & 4,72 & 11.421 & 1,02 & 0,13 & 13.122 & 1,04 & 0,15 & 5.015 & 1,06 & 0,06 \\
\hline 2006 & 93.602 & 6,70 & 11.692 & 1,02 & 0,12 & 14.015 & 1,07 & 0,15 & 5.338 & 1,06 & 0,06 \\
\hline 2007 & 100.062 & 6,90 & 12.149 & 1,04 & 0,12 & 15.024 & 1,07 & 0,15 & 5.702 & 1,07 & 0,06 \\
\hline 2008 & 103.611 & 3,55 & 12.103 & 1,00 & 0,12 & 15.116 & 1,01 & 0,15 & 5.959 & 1,05 & 0,06 \\
\hline 2009 & 105.322 & 1,65 & 12.024 & 0,99 & 0,11 & 14.489 & 0,96 & 0,14 & 6.147 & 1,03 & 0,06 \\
\hline 2010 & 109.499 & 3,97 & 12.047 & 1,00 & 0,11 & 14.754 & 1,02 & 0,13 & 6.370 & 1,04 & 0,06 \\
\hline 2011 & 116.721 & 6,60 & 12.297 & 1,02 & 0,11 & 15.455 & 1,05 & 0,13 & 6.796 & 1,07 & 0,06 \\
\hline 2012 & 121.441 & 4,04 & 12.605 & 1,03 & 0,10 & 15.467 & 1,00 & 0,13 & 7.140 & 1,05 & 0,06 \\
\hline
\end{tabular}

Fuente: Elaboración propia a partir de Cuentas Nacionales del DANE, mediante empalme de series base 1994 y 2005

Ahora bien, el estudio revela que las reformas del nuevo modelo, puestas en marcha a partir de 1990, no han surtido los efectos de lograr mayor competitividad, productividad, tecnificación ni conquista de los mercados internacionales por parte de los dos sectores claves de la economía, el agropecuario y el industrial, en lo que tiene que ver con el crecimiento de aquella, luego de tan largo plazo en la implementación de la libre competencia. En efecto, el sector agropecuario pasó de participar con el $16 \%$ en el 
comienzo de la última década del siglo anterior al $10 \%$ en diciembre de 2012. En forma similar se comportó el sector industrial, que pasó del $18 \%$ al $13 \%$ en el mismo rango. Algunos autores consideran esta situación como una desindustrialización, ocasionada por la competencia desleal a causa de la desgravación y desprotección a que fue sometido el sector. La actividad financiera se mantuvo con una participación estable al aumentar levemente del $4 \%$ al $6 \%$ en los 23 años de estudio.

\subsection{El empleo}

Comparado con el comportamiento del empleo generado por el sector industrial en la década del 70 al 80, el del segundo periodo analizado tuvo un ritmo menor. Así pues, al crecer a una tasa anual del 1,62 \%, entre 1990 y 2012, la situación contrasta con la mayor variación del periodo precedente, 2,14 \%. Se evidencia un repunte importante del 29,16\% en el 1992 con respecto al año anterior. Durante el resto del periodo de análisis, las tasas fueron fluctuantes y relativamente bajas, especialmente al acercarse el cambio de siglo, entre 1998 y 1999, cuando decreció en 5,97 \% y 10,05\%, respectivamente, según se puede apreciar en el gráfico 3.

Gráfico 3. Personal ocupado en la industria entre 1990 y 2012

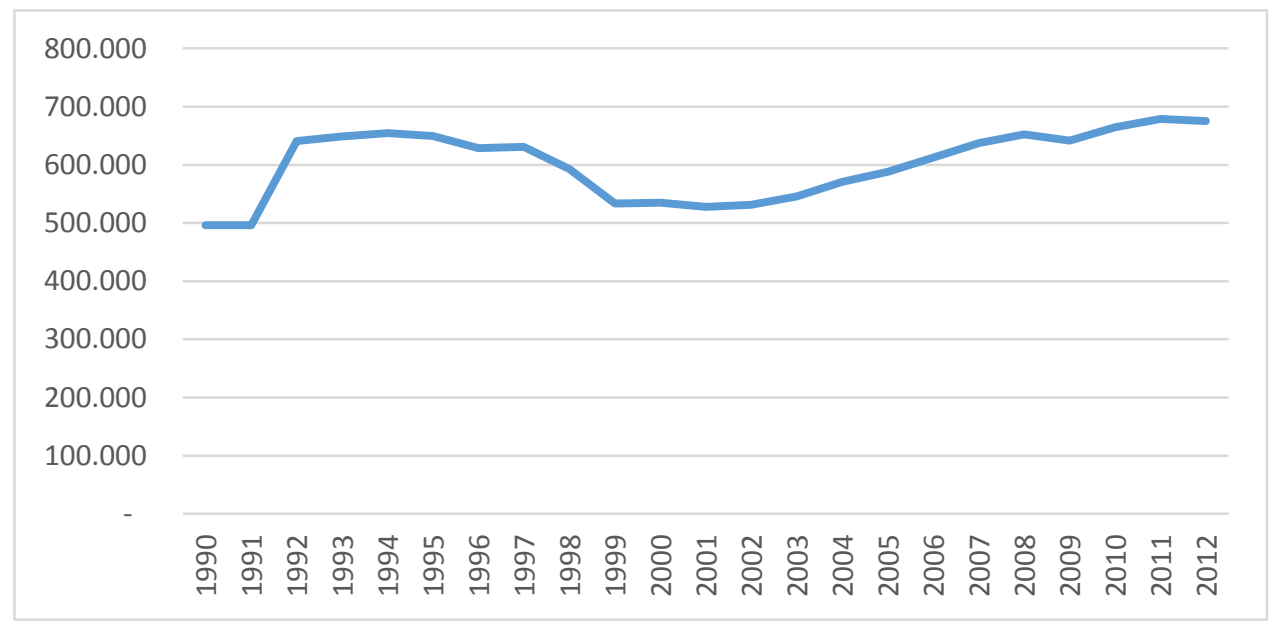

Fuente: DANE. Encuesta Anual Manufacturera. 
En términos absolutos, se pasó de generar 496.193 plazas de trabajo en el 90 a 674.971 al finalizar el 2012, para un incremento de 178.778 empleos, lo cual significa un promedio anual de 7.772, frente a uno similar entre el 70 y 89, cuando se situó en 7.271. Estas cifras de bajo crecimiento del empleo no reflejan los objetivos de las medidas de flexibilización laboral iniciadas con la Ley 50 de 1990.

Según Isaza $(2003,13)$ :

Esta Ley estuvo orientada a facilitar la creación de nuevos empleos, al introducir modificaciones a la legislación para hacer menos costosa la contratación y el despido de personal. Entre las disposiciones más importantes estuvieron la flexibilización de los contratos temporales, la facilitación del despido del trabajador después de diez años de antigüedad, la adopción de un sistema de salario que integrara todas las remuneraciones para los trabajadores de mayores ingresos (10 salarios mínimos) y la eliminación de los sobrecostos que implicaba el anterior régimen de cesantías.

En este sentido la flexibilización pretendía la reducción de los costos salariales a través de la creación de contratos temporales con un salario integral. Se abrió la facilidad de despido del trabajador después de diez años de antigüedad, disminuyendo el monto de las indemnizaciones y la creación de las empresas temporales para facilitar la contratación de personal. En tales condiciones, este no tiene posibilidad de exigir mejoras en las condiciones laborales establecidas previamente en las convenciones colectivas de las empresas.

El tema de la flexibilización laboral se continuó mediante la Ley 789 de 2002, de manera especial al reducir las prestaciones (parte del salario básico del trabajador), y aumentar las horas de trabajo. De esta manera, se incidió básicamente en la reducción de costos para el empresario al aumentar la jornada diurna de seis de la mañana a diez de la noche, cuando antes de dicha ley era de seis de la mañana a seis de la tarde. La jornada nocturna se estableció desde las diez pm hasta las seis am, cuando antes el horario correspondía entre las seis de la tarde hasta las seis horas del otro día. En cuanto al pago de dominicales y festivos, este pasó del $100 \%$ del valor de un día normal de trabajo a un 75 $\%$. El recargo nocturno, por lo tanto, se empezó a pagar con el $35 \%$ adicional, equivalente al valor de una hora de trabajo normal y solo a partir de las diez pm y no a partir de las seis de la tarde.

En síntesis, la tesis de reducir los costos laborales en la industria manufacturera colombiana como forma para generar empleo, no se evidencia en la investigación realizada, según las cifras ya referidas. Entre tanto, en los últimos años, el ahorro para los empresarios ha aumentado con esa reforma e incluso más con la reforma tributaria del 2012 que les 
alivió el pago de las contribuciones parafiscales tales como Sena, ICBF y cajas de compensación.

Como consecuencias de las reformas mencionadas, transcurrido un plazo relativamente largo, se constatan la desigualdad social en el país y la concentración del ingreso, dada la ampliación de la brecha entre los ingresos de los trabajadores y la acumulación del capital. $\mathrm{Si}$ se tiene en cuenta que el monto correspondiente a los salarios representa aproximadamente las dos terceras partes del ingreso nacional, la demanda agregada se afecta seriamente y por ende la generación de empleo en la economía. Según Keynes (1994), el salario no es solo un precio de un mercado particular y un elemento de costo para las empresas, sino uno de los componentes básicos de la demanda agregada, cuya reactivación estimula a los empresarios a crear nuevos empleos.

\subsection{Salarios y productividad}

Al examinar en forma global la productividad de la industria entre 1990 y 2012 , se registra una tasa promedio de crecimiento anual del 3,68 \%, es decir, un aumento frente a los años 70 - 89 cuando fue del $3 \%$. En contraste, el salario real evolucionó a un ritmo promedio de 1,65 \%, cuando en el periodo anterior superó a la productividad al llegar a $3,58 \%$. Estos resultados indican que los trabajadores aportaron mayores tasas de crecimiento de la productividad a costa de una reducción en sus salarios reales, para un diferencial por debajo de la productividad de $2,03 \%$, mientras en el lapso anterior esta diferencia superaba a la productividad en 0,58 \%. De los indicadores referidos se puede inferir, por lo tanto, un aumento de las utilidades que no corresponde con el reajuste de los salarios, de acuerdo con los beneficios obtenidos.

Una cuantificación de la relación entre los salarios reales y la productividad para el total de la industria durante el lapso que ahora se analiza, revela una débil correlación del 0,36 y coeficiente de determinación de solo 0,09, es decir, una implicación baja de la productividad sobre los salarios. Aumentos en la jornada de trabajo con la simultánea reducción de la remuneración por el trabajo extra explican el distanciamiento de la productividad y el salario, con las consabidas consecuencias sobre el consumo y el nivel de vida de la clase trabajadora.

En el gráfico 4 se muestra la superioridad de las tasas de crecimiento de la productividad laboral con respecto a la evolución de los salarios reales. Allí aparece como excepción el año 1992, cuando el salario repunta en 14,19 \% frente a una reducción de la productividad 
del 19,75 \%; luego se repite este comportamiento pero en menor intensidad para el 2008, cuando el salario aumentó 3,97 \% mientras la productividad se redujo en 3,23\%. Con preocupación se destacan los años con variación negativa entre 1996 y 2004, en especial 1996 con $-5,73 \%$; 1998, con $-5,31 \%$; 1999, con $-3,39 \%$ y 2000 con $-3,60 \%$; datos de salarios reales libres de la inflación.

Gráfico 4. Variación porcentual de los salarios y la productividad en la industria entre 1990 y 2012

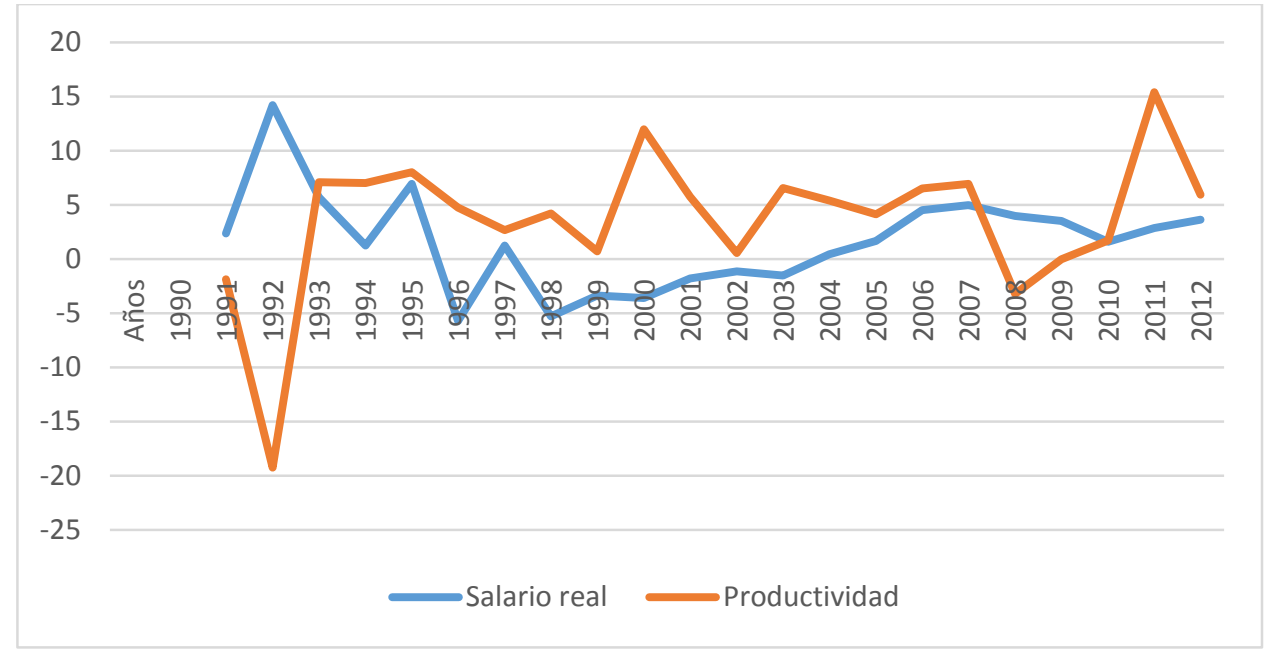

Fuente: Elaboración propia.

\subsection{La Producción bruta}

La evolución anual de la producción bruta del sector industrial alcanzó una tasa relativamente alta del $5,08 \%,(4,84 \%$ entre el 1970 y 1989) y superior al crecimiento del PIB (3,54 \%). Por su parte, uno de los dos grandes componentes -el consumo intermedio - experimentó una tasa superior de variación anual $(5,20 \%)$, como resultado de la desgravación a raíz de la apertura, de manera importante para insumos y bienes de capital. El valor agregado creció a un ritmo del 5,07 \%, de tal modo que los ingresos por salarios fueron desplazados por las utilidades empresariales: mientras los salarios participaron con el $25 \%$ en el 90, en 2012 cayeron al $12 \%$. En cuanto a contribución de estos dos importantes componentes en la producción, el consumo intermedio mantuvo una alta tasa, en promedio del $57 \%$, y el valor agregado del orden del $43 \%$. Estas cifras señalan la medida en que la industria ha sustituido trabajo interno (valor agregado) por trabajo externo (consumo intermedio), tanto por la reducción de aranceles como por la revaluación del peso durante gran parte de los años de análisis, lo que permitió la importación de materias primas y maquinaria para hacer más eficiente el proceso de producción y por lo tanto elevar la productividad. 


\section{Marco metodológico y modelo econométrico}

\subsection{Pruebas de raíz unitaria}

Para esta prueba de regresión se utiliza el test de Im, Pesaram y Shin (IPS) de la ADF convencional, según una muestra o universo $(\mathrm{N})$ de categorías, que en este caso son las agrupaciones industriales, a través del tiempo t, según la siguiente ecuación:

$$
\Delta \mathrm{Yi}, \mathrm{t}=\alpha \mathrm{i}+\pi \mathrm{it}+\beta \mathrm{i} \mathrm{Yi,t}-1+\sum_{\mathrm{J}=1}^{\mathrm{k}} \Psi \mathrm{i}, \mathrm{j} \mathrm{yi}_{\mathrm{t}} \mathrm{t} \mathrm{j}+\varepsilon \mathrm{i}, \mathrm{t}
$$

Donde, $\Delta$ es operador de diferencia de primer orden.

Yit son los salarios reales que son función lineal de la productividad real, que es la variable explicativa.

$\mathrm{i}=1,2, \ldots \mathrm{N}$, Indica las agrupaciones industriales (CIIU) a tres dígitos.

$\mathrm{T}=1,2, \ldots \mathrm{T}$. Corresponde $\mathrm{a}$ las observaciones en el tiempo. $\varepsilon \mathrm{i}=$ Término de perturbación de ruido blanco con varianza $\sigma^{2}$.

$\Delta$ yi,t-j = Término del lado derecho de la ecuación (1) que permite la correlación serial, con el objetivo de lograr el término de perturbación de ruido blanco.

ADF es la prueba Dickey-Fuller Aumentada. Es una prueba de raíz unitaria para una muestra de serie de tiempo. Es una versión aumentada de la prueba DickeyFuller para un conjunto más amplio y más complejo de modelos de series de tiempo. La estadística Dickey-Fuller Aumentada (ADF), utilizada para este caso, es un número negativo. Cuanto más negativo es, más fuerte es el rechazo de la hipótesis nula de que existe una raíz unitaria para un cierto nivel de confianza.

La hipótesis nula de raíz unitaria del panel se prueba al hacer beta ( $\beta$ ) igual a cero en la ecuación (1). La hipótesis alternativa es que todas las series son procesos estacionarios. La formulación de la hipótesis alternativa para beta es para diferenciar los grupos del panel.

\subsection{Prueba de cointegración de Pedroni}

Para el panel de cointegración o relación de largo plazo entre las dos variables en el modelo utilizado, simplemente se siguió el procedimiento propuesto por Pedroni 
(1999), que puede demostrarse mediante la siguiente regresión de panel de cointegración:

$\mathrm{Yi}, \mathrm{t}=\alpha \mathrm{i}+\rho \mathrm{it}+\beta 1 \mathrm{i} \times 1 \mathrm{i}, \mathrm{t}+\ldots \ldots+\beta \mathrm{Mi} \times \mathrm{Mi}, \mathrm{t}+\varepsilon \mathrm{i}, \mathrm{t}$

Para $\mathrm{t}=1, \ldots \mathrm{T} ; \quad \mathrm{i}=1, \ldots \mathrm{N} ; \mathrm{m}=1, \ldots \mathrm{M}$ y donde $\mathrm{T}$ se refiere al número de observaciones en el tiempo; $\mathrm{N}$, al número de agrupaciones industriales (CIIU) en el panel, y M, al número de variables de regresión. De acuerdo con Pedroni (1999), se construyeron las siete estadísticas, a saber: el panel de v-estadística, el panel de $\rho$ estadística, el panel estadístico $\mathrm{t}$ (no paramétrico), el panel estadístico $\mathrm{t}$ (paramétrico), el grupo de $\rho$-estadística, el grupo t-estadístico (no paramétrico) y el grupo t- estadístico (paramétrico), para poner a prueba el panel de cointegración.

\subsection{OLS totalmente modificado}

Con el fin de mostrar la relación individual de las agrupaciones industriales (CIIU) entre los salarios reales y la productividad laboral real, se empleó el modelo OLS totalmente modificado (FMOLS), estimador propuesto por Pedroni (2000 y 2001). 


\section{Resultados del trabajo empírico. Análisis econométrico}

\subsection{Datos}

Para el presente estudio se utilizaron datos anuales en los periodos 1970 - 1989 y 1990 2012. Como variables se consideraron los salarios reales y la productividad laboral, a nivel de las agrupaciones industriales o subsectores, clasificados a tres dígitos según la CIIU, obtenidas de la Encuesta Anual Manufacturera del DANE. Los códigos a tres dígitos seleccionados para el estudio y los respectivos nombres de las industrias se transcriben en el Anexo1. Las cifras de los salarios y de la productividad se trabajan a precios contantes de 1990. Para los salarios se tomó el Índice de Precio al Consumidor como deflactor y para la producción el Índice de Precios al Productor sector Industrial, ambos indicadores con fuente DANE.

El concepto de salario real corresponde al salario básico (remuneración), más las prestaciones sociales. Por otra parte, la productividad real se obtuvo tomando la producción bruta real por empleado, es decir, la productividad media del trabajo. La CIIU revisión 2 operó hasta el año 2000 con una clasificación de 28 agrupaciones y al entrar al siglo se implementó la CIIU revisión 3, ampliando las categorías a 62. A través de un trabajo de correspondencia de la CIIU 2 con la CIIU 3, a lo largo de los dos periodos se presenta una sola clasificación según la CIIU 2, a tres dígitos, para 28 subsectores.

\subsection{Pruebas de raíz unitaria para cada una de las variables}

La aplicación de la metodología ARIMA precisa la utilización de series económicas estacionarias en media y varianza. Cuando una serie no es estacionaria, o lo que es lo mismo, cuando no es integrada de orden cero I (0), se dice que presenta al menos una raíz unitaria. Si esto ocurre, es posible la obtención de una serie estacionaria mediante una sencilla transformación de la serie original como es la diferenciación adecuada. Los datos de panel pueden presentar dependencia de la sección transversal, debido a la presencia de shocks comunes (ciclos económicos), que afectan a todos los subsectores industriales y componentes no observados que se convierten en parte del error. 


\subsection{Pruebas de raíz unitaria para el periodo 1970-1989}

\section{Salario real y Productividad real}

Luego de varios ensayos y corridas de la prueba ADF que utiliza el test de Im, Pesaran y Shin (IPS), para detectar raíz unitaria, se tomaron varias alternativas tales como incluir intercepto, intercepto y tendencia, tanto en niveles como en primera diferencia para rechazar la hipótesis nula de presencia de raíz unitaria. Para los salarios reales, solo acudiendo a la prueba con intercepto y en primera diferencia, se logró rechazar la hipótesis nula de la presencia de raíz unitaria, al presentar el más alto W-estadístico negativo: 18.7660 con una probabilidad de 0.0000 . Respecto de la productividad se consiguió el rechazo de la hipótesis nula incluyendo intercepto y tendencia, y tomando primera diferencia, al presentar el más alto W-estadístico negativo: - 16.5807, con una probabilidad del 0.0000. A continuación se exponen los diferentes resultados para el total del sector industria y luego para la prueba definitiva a nivel desagregado para cada variable.

En la tabla 3 se discriminan los resultados de la prueba de raíz unitaria IPS panel.

Tabla 3. Resultados de la prueba de raíz unitaria IPS panel

\begin{tabular}{|l|l|l|}
\hline \multicolumn{1}{|c|}{ Variables } & \multicolumn{1}{|c|}{$\begin{array}{c}\text { W- } \\
\text { estadístico }\end{array}$} & Probabilidad \\
\hline Salario real (niveles) Intercepto & 4.77016 & 1.0000 \\
\hline Salario real ( primera diferencia) Intercepto & $-18.7660 * * *$ & 0.0000 \\
\hline Salario real (niveles) Intercepto y tendencia & 1.03108 & 0.1513 \\
\hline Salario real (primera diferencia) Intercepto y tendencia & -16.1231 & 0.0000 \\
\hline Productividad real (niveles) Intercepto & 10.1117 & 1.0000 \\
\hline Productividad real ( primera diferencia) Intercepto & -14.2431 & 0.0000 \\
\hline Productividad real (niveles) Intercepto y tendencia & 1.39702 & 0.9188 \\
\hline $\begin{array}{l}\text { Productividad real(primera diferencia)Intercepto y } \\
\text { tendencia }\end{array}$ & $-16.5807 * * *$ & 0.0000 \\
\hline
\end{tabular}

Nota: *** estadístico significativo al $1 \%$ de confianza

Los anteriores resultados implican que los paneles del salario real y la productividad real están integrados en primer orden, lo cual constituye un paso inicial importante en el análisis de panel de cointegración en cuanto a las propiedades integracionales de las series de datos económicos. Estas propiedades se cumplen a nivel de cada una de las agrupaciones industriales. La tabla 4 permite mostrar los resultados de la prueba de raíz unitaria para el salario real. Así mismo, en la tabla 5 se expone la Prueba de raíz unitaria para la productividad real. 
Tabla 4. Prueba de raíz unitaria para salario real a nivel de agrupaciones industriales. Primera diferencia con intercepto

Salario real - Primera diferencia

Null Hypothesis: Unit root (individual unit root process)

Series: D(SALARIO_REAL)

Date: 11/24/15 Time: 14:08

Sample: 19701989

Exogenous variables: Individual effects

Automatic selection of maximum lags

Automatic lag length selection based on SIC: 0 to 3

Total number of observations: 493

Cross-sections included: 28

\begin{tabular}{|c|c|c|c|c|c|c|c|}
\hline \multicolumn{5}{|l|}{ Method } & \multicolumn{2}{|l|}{ Statistic } & \multirow{2}{*}{$\frac{\text { Prob. }^{* *}}{0.0000}$} \\
\hline Im, Pesaran and & -stat & & & & -18.7660 & & \\
\hline \multicolumn{8}{|c|}{ ** Probabilities are computed assuming asympotic normality } \\
\hline \multicolumn{8}{|c|}{ Intermediate ADF test results } \\
\hline $\begin{array}{l}\text { Cross } \\
\text { section }\end{array}$ & $\mathrm{t}$-Stat & Prob. & $E(t)$ & $\mathrm{E}(\mathrm{Var})$ & Lag & $\begin{array}{l}\text { Max } \\
\text { Lag }\end{array}$ & Obs \\
\hline $311-312$ & -4.0077 & 0.0079 & -1.508 & 0.973 & 1 & 3 & 17 \\
\hline 390 & -5.5795 & 0.0003 & -1.519 & 0.880 & 0 & 3 & 18 \\
\hline 385 & -5.6466 & 0.0003 & -1.508 & 0.973 & 1 & 3 & 17 \\
\hline 384 & -3.5796 & 0.0175 & -1.519 & 0.880 & 0 & 3 & 18 \\
\hline 383 & -4.7534 & 0.0016 & -1.519 & 0.880 & 0 & 3 & 18 \\
\hline 382 & -3.8056 & 0.0111 & -1.519 & 0.880 & 0 & 3 & 18 \\
\hline 381 & -4.4179 & 0.0035 & -1.508 & 0.973 & 1 & 3 & 17 \\
\hline 372 & -5.7554 & 0.0002 & -1.519 & 0.880 & 0 & 3 & 18 \\
\hline 371 & -3.4996 & 0.0205 & -1.519 & 0.880 & 0 & 3 & 18 \\
\hline 369 & -4.9184 & 0.0012 & -1.519 & 0.880 & 0 & 3 & 18 \\
\hline 362 & -4.4651 & 0.0029 & -1.519 & 0.880 & 0 & 3 & 18 \\
\hline 361 & -4.5624 & 0.0024 & -1.519 & 0.880 & 0 & 3 & 18 \\
\hline 356 & -6.8241 & 0.0000 & -1.519 & 0.880 & 0 & 3 & 18 \\
\hline 355 & -6.7512 & 0.0000 & -1.519 & 0.880 & 0 & 3 & 18 \\
\hline 354 & -4.4874 & 0.0028 & -1.519 & 0.880 & 0 & 3 & 18 \\
\hline 353 & -7.4511 & 0.0000 & -1.508 & 0.973 & 1 & 3 & 17 \\
\hline 352 & -4.7929 & 0.0015 & -1.519 & 0.880 & 0 & 3 & 18 \\
\hline 351 & -5.4462 & 0.0004 & -1.519 & 0.880 & 0 & 3 & 18 \\
\hline 342 & -5.6817 & 0.0003 & -1.508 & 0.973 & 1 & 3 & 17 \\
\hline 341 & -5.0341 & 0.0009 & -1.519 & 0.880 & 0 & 3 & 18 \\
\hline 332 & -4.0595 & 0.0066 & -1.519 & 0.880 & 0 & 3 & 18 \\
\hline 331 & -4.3932 & 0.0034 & -1.519 & 0.880 & 0 & 3 & 18 \\
\hline 324 & -4.7312 & 0.0017 & -1.519 & 0.880 & 0 & 3 & 18 \\
\hline 323 & -7.0790 & 0.0000 & -1.519 & 0.880 & 0 & 3 & 18 \\
\hline 322 & -5.8809 & 0.0002 & -1.519 & 0.880 & 0 & 3 & 18 \\
\hline 321 & -3.2052 & 0.0387 & -1.395 & 1.056 & 2 & 3 & 16 \\
\hline 314 & -4.1623 & 0.0058 & -1.508 & 0.973 & 1 & 3 & 17 \\
\hline 313 & -2.2924 & 0.1863 & -1.366 & 1.181 & 3 & 3 & 15 \\
\hline Average & -4.9023 & & -1.507 & 0.917 & & & \\
\hline
\end{tabular}


Tabla 5. Prueba de raíz unitaria para la productividad real a nivel de agrupaciones industriales. Primera diferencia con intercepto y tendencia

Productividad Real - Primera diferencia

Null Hypothesis: Unit root (individual unit root process)

Series: D(PRODUCTIVIDAD_REAL)

Date: 11/24/15 Time: 15:49

Sample: 19701989

Exogenous variables: Individual effects, individual linear trends

Automatic selection of maximum lags

Automatic lag length selection based on SIC: 0 to 3

Total number of observations: 492

Cross-sections included: 28

\begin{tabular}{lcc}
\hline \hline Method & Statistic & Prob. $^{* *}$ \\
\hline Im, Pesaran and Shin W-stat & -16.5807 & 0.0000 \\
\hline \hline
\end{tabular}

** Probabilities are computed assuming asympotic normality

Intermediate ADF test results

\begin{tabular}{|c|c|c|c|c|c|c|c|}
\hline $\begin{array}{c}\text { Cross } \\
\text { section }\end{array}$ & $\mathrm{t}$-Stat & Prob. & $E(t)$ & $\mathrm{E}$ (Var) & Lag & $\begin{array}{l}\text { Max } \\
\text { Lag }\end{array}$ & Obs \\
\hline $311-312$ & -3.7394 & 0.0459 & -2.168 & 0.805 & 0 & 3 & 18 \\
\hline 390 & -5.5548 & 0.0019 & -2.170 & 0.923 & 1 & 3 & 17 \\
\hline 385 & -5.8159 & 0.0012 & -2.170 & 0.923 & 1 & 3 & 17 \\
\hline 384 & -4.1237 & 0.0229 & -2.168 & 0.805 & 0 & 3 & 18 \\
\hline 383 & -7.5442 & 0.0001 & -2.168 & 0.805 & 0 & 3 & 18 \\
\hline 382 & -3.6008 & 0.0586 & -2.168 & 0.805 & 0 & 3 & 18 \\
\hline 381 & -5.5705 & 0.0016 & -2.168 & 0.805 & 0 & 3 & 18 \\
\hline 372 & -8.5801 & 0.0000 & -2.168 & 0.805 & 0 & 3 & 18 \\
\hline 371 & -3.5640 & 0.0624 & -2.168 & 0.805 & 0 & 3 & 18 \\
\hline 369 & -4.8348 & 0.0068 & -2.170 & 0.923 & 1 & 3 & 17 \\
\hline 362 & -4.5434 & 0.0114 & -2.170 & 0.923 & 1 & 3 & 17 \\
\hline 361 & -4.0902 & 0.0243 & -2.168 & 0.805 & 0 & 3 & 18 \\
\hline 356 & -5.6977 & 0.0012 & -2.168 & 0.805 & 0 & 3 & 18 \\
\hline 355 & -5.4529 & 0.0020 & -2.168 & 0.805 & 0 & 3 & 18 \\
\hline 354 & -4.2212 & 0.0233 & -1.977 & 1.214 & 3 & 3 & 15 \\
\hline 353 & -6.8170 & 0.0002 & -2.170 & 0.923 & 1 & 3 & 17 \\
\hline 352 & -4.8970 & 0.0055 & -2.168 & 0.805 & 0 & 3 & 18 \\
\hline 351 & -7.4994 & 0.0001 & -2.168 & 0.805 & 0 & 3 & 18 \\
\hline 342 & -4.8862 & 0.0056 & -2.168 & 0.805 & 0 & 3 & 18 \\
\hline 341 & -4.8841 & 0.0056 & -2.168 & 0.805 & 0 & 3 & 18 \\
\hline 332 & -4.1240 & 0.0229 & -2.168 & 0.805 & 0 & 3 & 18 \\
\hline 331 & -4.5033 & 0.0123 & -2.170 & 0.923 & 1 & 3 & 17 \\
\hline 324 & -3.9751 & 0.0315 & -2.170 & 0.923 & 1 & 3 & 17 \\
\hline 323 & -3.5917 & 0.0633 & -2.009 & 1.005 & 2 & 3 & 16 \\
\hline 322 & -3.5237 & 0.0670 & -2.168 & 0.805 & 0 & 3 & 18 \\
\hline 321 & -4.0241 & 0.0275 & -2.168 & 0.805 & 0 & 3 & 18 \\
\hline 314 & -3.9303 & 0.0326 & -2.168 & 0.805 & 0 & 3 & 18 \\
\hline 313 & -7.9714 & 0.0000 & -2.168 & 0.805 & 0 & 3 & 18 \\
\hline Average & -5.0557 & & -2.156 & 0.857 & & & \\
\hline
\end{tabular}




\subsection{Los resultados de cointegración}

La prueba de cointegración se basa en las siete pruebas estadísticas propuestas por Pedroni (1999). En la tabla 6 se presentan los resultados para el modelo planteado, donde los salarios reales dependen de la productividad, es decir, los salarios constituyen la variable dependiente y la productividad la variable independiente. Se encontró que, al utilizar intercepto y tendencia, este modelo presenta cinco pruebas significativas de la siete propuestas, lo cual apoya la evidencia de cointegración. Con base en tales indicadores y resultados se concluye que los salarios reales versus productividad real están cointegrados para el panel de las 28 agrupaciones industriales.

\section{Tabla 6. Prueba del panel de cointegración}

Intercepto y tendencia

Pedroni Residual Cointegration Test

Series: SALARIO_REAL PRODUCTIVIDAD_REAL

Date: 11/24/15 Time: 15:56

Sample: 19701989

Included observations: 560

Cross-sections included: 28

Null Hypothesis: No cointegration

Trend assumption: Deterministic intercept and trend

Automatic lag length selection based on SIC with a max lag of 3

Newey-West automatic bandwidth selection and Bartlett kernel

\begin{tabular}{l} 
Alternative hypothesis: common AR coefs. (within-dimension) \\
\\
\cline { 2 - 5 }
\end{tabular}

Alternative hypothesis: individual AR coefs. (between-dimension)

Group rho-Statistic

\begin{tabular}{cc} 
Statistic & Prob. \\
\hline 0.540361 & 0.7055 \\
-6.103246 & 0.0000 \\
-8.303614 & 0.0000
\end{tabular}

Group PP-Statistic 


\subsection{FMOLS: Modelo de mínimos cuadrados ordinario totalmente modificado}

Una vez cumplidos los requisitos de estacionariedad y coitegración entre las variables del modelo propuesto — salarios en función de la productividad—, se implementó el FMOLS para el total de las 28 agrupaciones industriales durante el periodo de análisis y se encontró una alta explicación de la productividad sobre los salarios del orden del 0.90, con alta significancia de la variable independiente (productividad), con $\mathrm{t}$ estadístico de 35523.05 para una probabilidad de 0.0000. El coeficiente angular reporta un valor de 590.3743 , indicando que un incremento de mil pesos en la productividad conlleva a un aumento del salario real en 590, 37 pesos. Los resultados en detalle se aprecian en la tabla 7 y permiten concluir que de 1970 a 1989 los incrementos en la productividad se reflejan en incrementos salariales de acuerdo con las teorías que estimula la demanda efectiva y el mantenimiento del poder adquisitivo de los salarios.

\section{Tabla 7. FMOLS}

Dependent Variable: SALARIO_REAL Method: Panel Fully Modified Least Squares (FMOLS)

Date: 11/24/15 Time: 16:39

Sample (adjusted): 19711989

Periods included: 19

Cross-sections included: 28

Total panel (balanced) observations: 532

Panel method: Weighted estimation

Cointegrating equation deterministics: $\mathrm{C}$

Long-run covariance estimates (Bartlett kernel, Newey-West fixed bandwidth)

\begin{tabular}{lcccc}
\hline \hline \multicolumn{1}{c}{ Variable } & Coefficient & Std. Error & t-Statistic & Prob. \\
\hline \hline PRODUCTIVIDAD_REAL & 590.3743 & 0.016619 & \multirow{2}{*}{35523.05} & 0.0000 \\
\hline \hline R-squared & 0.906045 & Mean dependent var & 30319950 \\
Adjusted R-squared & 0.900815 & S.D. dependent var & 29554915 \\
S.E. of regression & 9307934. & Sum squared resid & $4.36 \mathrm{E}+16$ \\
Durbin-Watson stat & 0.240527 & Long-run variance & $7.55 \mathrm{E}+13$ \\
\hline \hline
\end{tabular}

\subsection{Pruebas de raíz unitaria para el periodo 1990-2012}

\section{Salario real y Productividad real}

Luego de varios ensayos y corridas de la prueba ADF que utiliza el test de Im, Pesaram y Shin ( IPS), para detectar raíz unitaria, se tomaron varias alternativas, tales como incluir intercepto, intercepto y tendencia, tanto en niveles como en primera diferencia para 
rechazar la hipótesis nula de presencia de raíz unitaria. Para los salarios reales, solo haciendo uso de la prueba con intercepto y en primera diferencia, se logró rechazar la hipótesis nula de la presencia de raíz unitaria, al presentar el más alto W-estadístico negativo: -13.5767 con una probabilidad de 0.0000 . Respecto de la productividad se obtuvo el rechazo de la hipótesis nula incluyendo solo intercepto tomando primera diferencia, al presentar el más alto W-estadístico negativo: - 18.6250 con una probabilidad del 0.0000. En las tablas 8, 9 y 10 se presentan los diferentes resultados para el total del sector industria y luego para la prueba definitiva a nivel desagregado para cada variable.

Tabla 8. Resultados de la prueba de raíz unitaria IPS panel

\begin{tabular}{|l|l|l|}
\hline \multicolumn{1}{|c|}{ Variables } & \multicolumn{1}{|c|}{$\begin{array}{c}\text { W- } \\
\text { estadístico }\end{array}$} & Probabilidad \\
\hline Salario real (niveles) Intercepto & -0.95396 & 0.1701 \\
\hline Salario real ( primera diferencia) Intercepto & $-13.5767 * * *$ & 0.0000 \\
\hline Salario real (niveles) Intercepto y tendencia & -0.14270 & 0.44433 \\
\hline Salario real (primera diferencia) Intercepto y tendencia & -11.8978 & 0.0000 \\
\hline Productividad real (niveles) Intercepto & 4.48571 & 1.0000 \\
\hline Productividad real ( primera diferencia) Intercepto & $-18.6250 * * *$ & 0.0000 \\
\hline Productividad real (niveles) Intercepto y tendencia & -4.28260 & 0.0000 \\
\hline $\begin{array}{l}\text { Productividad real(primera diferencia)Intercepto y } \\
\text { tendencia }\end{array}$ & -17.1775 & 0.0000 \\
\hline
\end{tabular}

Nota: *** estadístico significativo al $1 \%$ de confianza

Tabla 9. Prueba de raíz unitaria para salario real a nivel de agrupaciones industriales. Primera diferencia con intercepto

Salario real - Primera diferencia. Intercepto

Null Hypothesis: Unit root (individual unit root process)

Series: D(SALARIO_REAL)

Date: 11/24/15 Time: 22:45

Sample: 19902012

Exogenous variables: Individual effects

Automatic selection of maximum lags

Automatic lag length selection based on SIC: 0 to 3

Total number of observations: 567

Cross-sections included: 28

\begin{tabular}{llc}
\hline \hline Method & Statistic & Prob. $^{* *}$ \\
\hline Im, Pesaran and Shin W-stat & -13.5767 & 0.0000 \\
\hline \hline
\end{tabular}

${ }^{* *}$ Probabilities are computed assuming asympotic normality

Intermediate ADF test results 


\begin{tabular}{cccccccc} 
section & $\mathrm{t}-\mathrm{Stat}$ & Prob. & $\mathrm{E}(\mathrm{t})$ & $\mathrm{E}(\mathrm{Var})$ & Lag & Lag & Obs \\
\hline $311-312$ & -1.7774 & 0.3786 & -1.394 & 1.095 & 3 & 4 & 18 \\
390 & -5.2121 & 0.0004 & -1.522 & 0.843 & 0 & 4 & 21 \\
385 & -5.3027 & 0.0004 & -1.522 & 0.843 & 0 & 4 & 21 \\
384 & -4.1400 & 0.0046 & -1.522 & 0.843 & 0 & 4 & 21 \\
383 & -2.4402 & 0.1435 & -1.522 & 0.843 & 0 & 4 & 21 \\
382 & -2.1847 & 0.2177 & -1.394 & 1.095 & 3 & 4 & 18 \\
381 & -2.4360 & 0.1465 & -1.394 & 1.095 & 3 & 4 & 18 \\
372 & -3.3950 & 0.0252 & -1.394 & 1.095 & 3 & 4 & 18 \\
371 & -3.9402 & 0.0072 & -1.522 & 0.843 & 0 & 4 & 21 \\
369 & -3.1750 & 0.0362 & -1.522 & 0.843 & 0 & 4 & 21 \\
362 & -3.1709 & 0.0365 & -1.522 & 0.843 & 0 & 4 & 21 \\
361 & -4.1763 & 0.0043 & -1.522 & 0.843 & 0 & 4 & 21 \\
356 & -3.5091 & 0.0187 & -1.516 & 0.915 & 1 & 4 & 20 \\
355 & -4.2482 & 0.0037 & -1.522 & 0.843 & 0 & 4 & 21 \\
354 & -4.5547 & 0.0024 & -1.394 & 1.095 & 3 & 4 & 18 \\
353 & -9.4225 & 0.0000 & -1.522 & 0.843 & 0 & 4 & 21 \\
352 & -3.5569 & 0.0176 & -1.420 & 0.991 & 2 & 4 & 19 \\
351 & -4.5351 & 0.0020 & -1.522 & 0.843 & 0 & 4 & 21 \\
342 & -5.4058 & 0.0003 & -1.522 & 0.843 & 0 & 4 & 21 \\
341 & -3.8792 & 0.0082 & -1.522 & 0.843 & 0 & 4 & 21 \\
332 & -3.9616 & 0.0069 & -1.522 & 0.843 & 0 & 4 & 21 \\
331 & -2.8458 & 0.0690 & -1.522 & 0.843 & 0 & 4 & 21 \\
324 & -3.7243 & 0.0115 & -1.522 & 0.843 & 0 & 4 & 21 \\
323 & -3.0822 & 0.0435 & -1.522 & 0.843 & 0 & 4 & 21 \\
322 & -4.0667 & 0.0055 & -1.522 & 0.843 & 0 & 4 & 21 \\
321 & -1.8082 & 0.3647 & -1.394 & 1.095 & 3 & 4 & 18 \\
314 & -7.4024 & 0.0000 & -1.522 & 0.843 & 0 & 4 & 21 \\
313 & -2.7037 & 0.0900 & -1.522 & 0.843 & 0 & 4 & 21 \\
Average & -3.9306 & & & & & & \\
& & & -1.490 & 0.904 & & & \\
\hline
\end{tabular}

Tabla 10. Prueba de raíz unitaria para la productividad real a nivel de agrupaciones industriales. Primera diferencia con intercepto

Productividad - Primera diferencia

Null Hypothesis: Unit root (individual unit root process)

Series: D(PRODUCTIVIDAD)

Date: $11 / 24 / 15$ Time: $22: 19$

Sample: 19902012

Exogenous variables: Individual effects

Automatic selection of maximum lags

Automatic lag length selection based on SIC: 0 to 2

Total number of observations: 580

Cross-sections included: 28

\begin{tabular}{lcc}
\hline \hline Method & Statistic & Prob. $^{* *}$ \\
\hline Im, Pesaran and Shin W-stat & -18.6250 & 0.0000 \\
\hline \hline
\end{tabular}

${ }^{* *}$ Probabilities are computed assuming asympotic normality

Intermediate ADF test results 


\begin{tabular}{cccccccc} 
section & $t-S t a t$ & Prob. & $E(t)$ & $E($ Var $)$ & Lag & Lag & Obs \\
\hline $311-312$ & -4.1154 & 0.0049 & -1.522 & 0.843 & 0 & 4 & 21 \\
390 & -6.3148 & 0.0000 & -1.522 & 0.843 & 0 & 4 & 21 \\
385 & -4.1665 & 0.0044 & -1.522 & 0.843 & 0 & 4 & 21 \\
384 & -4.7634 & 0.0012 & -1.522 & 0.843 & 0 & 4 & 21 \\
383 & -2.9138 & 0.0606 & -1.522 & 0.843 & 0 & 4 & 21 \\
382 & -5.1907 & 0.0005 & -1.522 & 0.843 & 0 & 4 & 21 \\
381 & -3.7853 & 0.0101 & -1.522 & 0.843 & 0 & 4 & 21 \\
372 & 0.6436 & 0.9870 & -1.420 & 0.991 & 2 & 4 & 19 \\
371 & -3.3124 & 0.0273 & -1.522 & 0.843 & 0 & 4 & 21 \\
369 & -5.6522 & 0.0002 & -1.516 & 0.915 & 1 & 4 & 20 \\
362 & -5.3641 & 0.0003 & -1.522 & 0.843 & 0 & 4 & 21 \\
361 & -5.7580 & 0.0002 & -1.516 & 0.915 & 1 & 4 & 20 \\
356 & -5.7152 & 0.0001 & -1.522 & 0.843 & 0 & 4 & 21 \\
355 & -7.7228 & 0.0000 & -1.522 & 0.843 & 0 & 4 & 21 \\
354 & -5.1835 & 0.0005 & -1.516 & 0.915 & 1 & 4 & 20 \\
353 & -5.3155 & 0.0004 & -1.516 & 0.915 & 1 & 4 & 20 \\
352 & -5.1177 & 0.0005 & -1.522 & 0.843 & 0 & 4 & 21 \\
351 & -5.0394 & 0.0006 & -1.522 & 0.843 & 0 & 4 & 21 \\
342 & -4.2495 & 0.0037 & -1.522 & 0.843 & 0 & 4 & 21 \\
341 & -5.3058 & 0.0004 & -1.522 & 0.843 & 0 & 4 & 21 \\
332 & -4.2927 & 0.0033 & -1.522 & 0.843 & 0 & 4 & 21 \\
331 & -5.0496 & 0.0006 & -1.522 & 0.843 & 0 & 4 & 21 \\
324 & -6.1703 & 0.0001 & -1.516 & 0.915 & 1 & 4 & 20 \\
& & & & & & & \\
323 & -5.3939 & 0.0003 & -1.522 & 0.843 & 0 & 4 & 21 \\
322 & -4.4051 & 0.0026 & -1.522 & 0.843 & 0 & 4 & 21 \\
321 & -4.7985 & 0.0012 & -1.516 & 0.915 & 1 & 4 & 20 \\
314 & -5.0675 & 0.0006 & -1.522 & 0.843 & 0 & 4 & 21 \\
313 & -4.5261 & 0.0020 & -1.522 & 0.843 & 0 & 4 & 21 \\
\hline & & & & & & & \\
Average & -4.7874 & & -1.517 & 0.863 & & & \\
\hline \hline & & & & & & &
\end{tabular}

\subsection{Los resultados de cointegración}

La prueba de cointegración se basa en las siete pruebas estadísticas propuestas por Pedroni (1999). En la tabla 11 se presentan los resultados para el modelo propuesto donde los salarios reales dependen de la productividad, es decir los salarios constituyen la variable dependiente y la productividad la variable independiente. Se encontró que utilizando solo intercepto este modelo presenta 5 pruebas significativas de la 7 propuesta, al tomar como probabilidad máximo el $10 \%$, lo cual apoya la evidencia de cointegración. Con base en estos indicadores y resultados se concluye que los salarios reales-productividad real están cointegrados para el panel de las 28 agrupaciones industriales. 
Tabla 11. Prueba del panel de cointegración. Intercepto

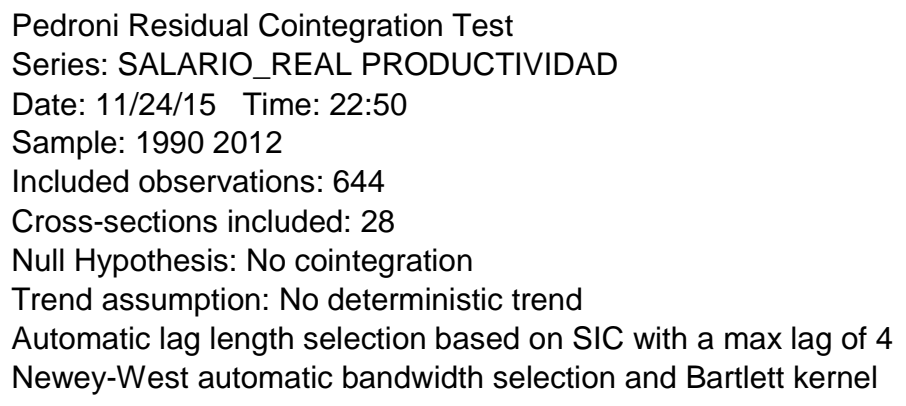

\begin{tabular}{cccc} 
Statistic & Prob. & $\begin{array}{c}\text { Weighted } \\
\text { Statistic }\end{array}$ & Prob. \\
\hline 2.129928 & 0.0166 & 0.319577 & 0.3746 \\
-1.581078 & 0.0569 & -0.216847 & 0.4142 \\
-2.844264 & 0.0022 & -1.238932 & 0.1077 \\
-3.046055 & 0.0012 & -1.613759 & 0.0533
\end{tabular}

Alternative hypothesis: individual AR coefs. (between-dimension)

Group rho-Statistic

Group PP-Statistic

Group ADF-Statistic

\begin{tabular}{cc} 
Statistic & Prob. \\
\hline 1.874794 & 0.9696 \\
0.242055 & 0.5956 \\
-1.533489 & 0.0626
\end{tabular}

\subsection{FMOLS: Modelo de mínimos cuadrados ordinarios totalmente modificado}

Una vez cumplido los requisitos de estacionariedad y cointegración entre las variables del modelo propuesto de los salarios en función de la productividad, se implementó el FMOLS para el total de las 28 agrupaciones industriales durante el periodo de análisis. Se encontró una alta explicación de la productividad sobre los salarios del orden del 0.95 , con alta significancia de la variable independiente (productividad), con t -estadístico de 878.0660 para una probabilidad de 0.0000 . El coeficiente angular reporta un valor de 12.23225 , lo que indica que un incremento de mil de pesos en la productividad conlleva a una reducción del salario real en 12,23 pesos. Los resultados en detalle se pueden observar en la tabla 12 y permiten concluir que de 1990 a 2012 los aumentos en la productividad se reflejan en disminuciones salariales, lo cual revela un incremento de las utilidades, al reducir costos salariales, afectando el consumo final de los trabajadores. Esta situación se manifiesta en el lento crecimiento de la economía en los años de estudio, sin lograr los objetivos de incrementar el empleo y contrayendo en última instancia la demanda efectiva. 


\section{Tabla 12. FMOLS}

Dependent Variable: SALARIO_REAL

Method: Panel Fully Modified Least Squares (FMOLS)

Date: 11/24/15 Time: 22:55

Sample (adjusted): 19912012

Periods included: 22

Cross-sections included: 28

Total panel (balanced) observations: 616

Panel method: Weighted estimation

Cointegrating equation deterministics: $\mathrm{C}$

Long-run covariance estimates (Bartlett kernel, Newey-West fixed bandwidth)

\begin{tabular}{lrlll}
\hline \hline \multicolumn{1}{c}{ Variable } & Coefficient & Std. Error & t-Statistic & Prob. \\
\hline \hline \multicolumn{1}{c}{ PRODUCTIVIDAD } & -12.23225 & 0.013931 & -878.0660 & 0.0000 \\
\hline \hline R-squared & 0.953178 & Mean dependent var & 45935583 \\
Adjusted R-squared & 0.950944 & S.D. dependent var & 49028838 \\
S.E. of regression & 10859171 & Sum squared resid & $6.92 \mathrm{E}+16$ \\
Durbin-Watson stat & 0.223484 & Long-run variance & $1.06 \mathrm{E}+14$ \\
\hline \hline
\end{tabular}




\section{Conclusiones}

Las reformas laborales que pretendían la flexibilización del mercado laboral, para el caso de la industria manufacturera en el periodo 1990 - 2012, no tuvieron los efectos positivos esperados en la generación de nuevas plazas de trabajo y sí repercutieron desfavorablemente en los salarios reales, según el análisis econométrico de la relación de causalidad de la productividad laboral sobre los salarios.

Es así como, al inicio del periodo de estudio, con la Ley 50 de 1990, el Estado consideró que la reforma laboral era necesaria para lograr un mercado de trabajo flexible. Se introdujeron modificaciones en la normatividad y legislación para hacer menos costosa la contratación y el despido de personal con miras a incrementar la demanda laboral. Es evidente que durante los años de estudio el pretendido incentivo de creación de nuevos empleos, al reducir el costo de los mismos, solo conllevó a una inestabilidad y precarización de las condiciones laborales.

Lo anterior significa que la reforma enmarcada en la coyuntura internacional generó efectos negativos en el empleo manufacturero, tanto en el corto como en el largo plazo. Ello explica los aumentos de productividad por la intensificación de la mano de obra ya contratada, al extender las jornadas de trabajo con la Ley 789 del 2002, al unísono de la reducción del pago de horas extras y festivos.

Los resultados del análisis estadístico descriptivo para el periodo 1990 - 2012 dejan percibir una situación preocupante de la industria manufacturera, en comparación con el periodo de 1970 - 1989, cuando operó el modelo de crecimiento con base en el mercado interno e incentivo a las exportaciones. En efecto, la industria pasó de participar con un promedio del $23 \%$ en el PIB, durante el lapso 1970 a 1989, a solo un $15 \%$ entre 1990 y 2012. La pérdida ha continuado en los últimos años, lo que ha llevado a algunos autores a denominar esta fase como de desindustrialización y periodo en el cual el mercado interno es la fuente principal de crecimiento ante la reducción de las exportaciones.

En cuanto al estudio econométrico y especialmente la cuantificación de la relación de causalidad de los salarios versus productividad laboral, los hallazgos igualmente revelan condiciones desfavorables en materia salarial durante los últimos veintitrés años, cuando al incrementarse la productividad laboral en mil pesos constantes, el salario real se contrajo en 12,23 pesos, mientras en los veinte años anteriores, por cada aumento de mil pesos constantes en la productividad, el salario real creció en 590,37 pesos. 
El estudio realizado permite esclarecer que la intención de las políticas comerciales, laborales y salariales van en contravía de los principios de redistribución de la riqueza, así como de la equidad social. El respeto a los derechos humanos de la clase trabajadora, que constituye el mayor porcentaje de la población del país, y del cual tanto se discute en la actualidad, debe ser un objetivo de la clase dirigente $\mathrm{y}$, en consecuencia, replantear las condiciones internas frente al gran capital industrial y financiero, así como en el plano externo se debe examinar la conveniencia de los tratados de libre comercio frente a la globalización, ante las condiciones precarias de un sector tan importante en toda economía como es la industria manufacturera. 


\section{Referencias}

Bhattacharya, M.; Narayan, P.; Popp, S. y Rath, B. (2010). The productivity -wage and productivity-employment nexus: a panel data analysis of Indian manufacturing, Empir Econ (40). DOI: 10.1007/s00181-010-0362, pp.285-303.

Departamento Administrativo Nacional de Estadística DANE, Cuentas Nacionales. Años 1970-1989 y 1990-2012

Departamento Administrativo Nacional de Estadística DANE, Encuesta Anual Manufacturera. Años 1970-1989 y 1990-2012

García I., J. G. (2002). Liberación y transformación en la industria colombiana, Revista Criterio, (31). Universidad Autónoma de Colombia, pp.113-120.

Isaza C., J. G. (2003). Flexibilización laboral: un análisis de sus efectos sociales para el caso colombiano, Revista Equidad y Desarrollo, (1).Universidad de La Salle, pp.940

Kalecky, M. (1956). Teoría de la dinámica económica. México DF: FCE.

Keynes, J. M. (1994). Teoría general de la ocupación, el interés y el dinero. Tercera reimpresión. Santafé de Bogotá, D.C.: FCE.

Méndez M., J. S. (1997). Fundamentos de Economía. México DF: Mc Graw-Hill.

Méndez S., J. A. y H. A. Hernández E. (2014). Relación de largo plazo y análisis de causalidad y sensibilidad entre los salarios reales y la productividad laboral en el sector manufacturero a partir de las cifras de los departamentos en Colombia, Revista Finanzas y Política Económica, 6 (2). Universidad Católica de Colombia/ Facultad de Economía, pp. 341-366.

Pedroni, P. (1999). Critical values for cointegration test in heterogeneous panel with multiple regressors, Oxf Bull Econ Stat (61), pp. 653-670.

Pedroni, P. (2000). Fully modified OLS for heterogeneous panels, Adv. Economy (15), pp. 93-130.

Pedroni, P. (2001). Purchasing power parity tests in cointegrated panels, Rev Econ Stat (83), pp. 727-731.

Sarmiento P., E. (2014). ¿Cuál es la gran causa de la desigualdad en el mundo? , El Tiempo, 17 de octubre. Bogotá DC, p. 13.

Sierra G., J. (2001). Diccionario Jurídico: Ajustado a la Legislación Colombiana. $3^{\mathrm{a}}$ ed. Medellín: Librería Jurídica Sánchez R.

Tejedor E., J. M. (2013). Editorial, Revista Finanzas y Política Económica, 5(2). Universidad Católica de Colombia / Facultad de Economía, pp.15-18 
Zhang, H. y M. Smith. (2012). Globalization and workplace performance in Canada: Crosssectional and dynamic analyses of productivity and wage outcomes, Research in Social Stratification and Mobility, 30(3). Montreal, Quebec, Canada, pp. 310-327.

Zhanga, J. y X. Liua. (2013). The evolving pattern of the wage-labor productivity nexus in China, Evidence from manufacturing firm-level data. Economic System, 37(3). Shanghai, China, pp. 354-368. 


\section{ANEXOS}

\section{Anexo 1. Clasificación CIIU Rev.2. 1970-1999}

Agrupaciones industriales

Código Nombre

311-312 Fabricación de productos alimenticios, excepto bebidas Bebidas

Tabaco Industria de madera, sus productos y corcho, excepto muebles Muebles de madera, y accesorios, excepto los que son principalmente metálicos Papel y sus productos Imprentas, editoriales y conexas Sustancias químicas industriales Otros productos químicos

Refinerías de petróleo Productos derivados del petróleo y del carbón Productos del caucho Productos plásticos Objetos de barro, loza y porcelana Vidrio y productos de vidrio Otros productos minerales, no metálicos Industrias básicas de hierro y acero Industrias básicas de metales no ferrosos Productos metálicos, excepto maquinaria y equipo Maquinaria, excepto la eléctrica Equipo y material de transporte Equipo profesional y científico, de medida y de control, fotográficos y Otras industrias manufactureras 
Anexo 2. Tabla correlativa CIIU Rev. 2 - CIIU Rev. 3 a.c.

$\begin{array}{ll}\text { CIIU Rev.2 } & \text { CIIU Rev.3 a.C. } \\ 311-312 & 151,152,153,154,155,156,157,158 \\ 313 & 159 \\ 314 & 160 \\ 321 & 171,172,173,174,175 \\ 322 & 181,182 \\ 323 & 191,193 \\ 324 & 192 \\ 331 & 201,202,203,204,209 \\ 332 & 361 \\ 341 & 210 \\ 342 & 221,222,223,224 \\ 351 & 241,243 \\ 352 & 242 \\ 353 & 232 \\ 354 & 232 \\ 355 & 251 \\ 356 & 252 \\ 361 & 269 \\ 362 & 261 \\ 369 & 269 \\ 371 & 271,273 \\ 372 & 272 \\ 381 & 281,289 \\ 382 & 291,292,293,300 \\ 383 & 311,312,313,314,315,319,321,322 \\ 384 & 341,342,343,351,352,353,359 \\ 385 & 323,331,332,333 \\ 390 & 369 \\ & \end{array}$

